\title{
Erratum to: Influence of the Pacific quasi-decadal oscillation on the monsoon precipitation in Nepal
}

\author{
Shih-Yu Wang • Robert R. Gillies
}

Published online: 18 July 2012

(C) Springer-Verlag 2012

\section{Erratum to: Clim Dyn \\ DOI 10.1007/s00382-012-1376-2}

The authors report an imagery error that occurred during the production process in the 2 nd page of the above paper. The affected figure (Fig. 1) is reprinted below with the domain corrected.
The online version of the original article can be found under doi:10.1007/s00382-012-1376-2.

\section{S.-Y. Wang $(\bowtie) \cdot$ R. R. Gillies}

Utah Climate Center, Utah State University, 4820 Old Main Hill, Logan, UT 84322-4820, USA

e-mail: simon.wang@usu.edu

S.-Y. Wang $\cdot$ R. R. Gillies

Department of Plants, Soils, and Climate,

Utah State University, Logan, UT, USA (a) Jul-Aug precipitation ( $\mathrm{mm} /$ day)

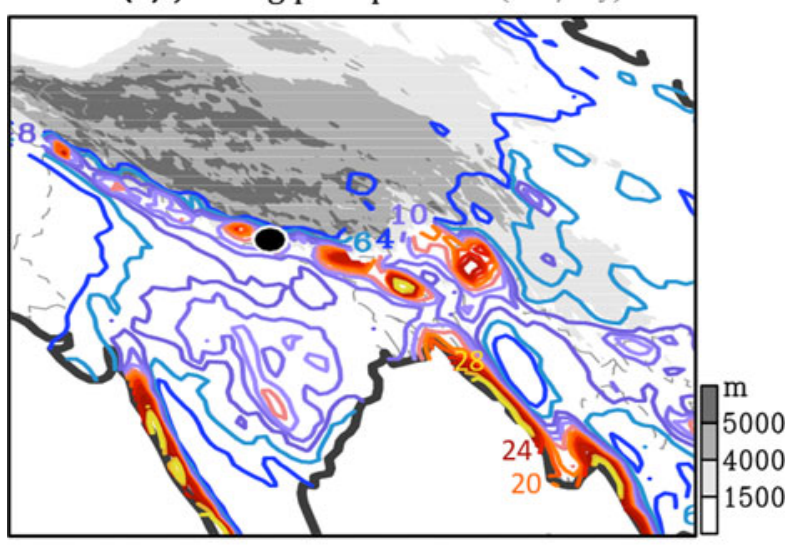

(b) Lightning frequency

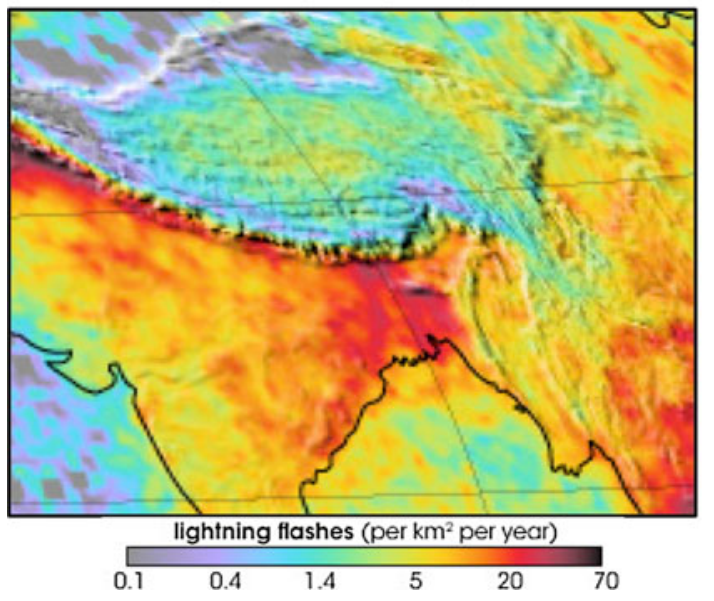

Fig. 1 a July-August climatology of precipitation (contours; mm/day) and the topography (shadings), and $\mathbf{b}$ annual lightning frequency between 1997 and 2002 derived from the Lightning Imaging Sensor onboard the TRMM satellite and between 1995 and 2000 by the Optical Transient Detector (Source: NASA Earth Observatory Webpage). The black dot in a marks Kathmandu, Nepal's capital city 